\title{
Tenckhoff Catheter Implantation in Refractory Ascites Due to Right Heart Failure
}

\author{
Chris Anthony ${ }^{1,2,3^{*}}$, Rominder Grover ${ }^{2}$, Roberto Spina ${ }^{2}$, Monica Bexton ${ }^{1}$, Lisa Paquin ${ }^{1}$, Anne M. Keogh ${ }^{3}$, \\ Christopher S. Hayward ${ }^{3}$, Peter S. Macdonald ${ }^{3}$, Jacob Sevastos ${ }^{4}$ \\ ${ }^{1}$ Department of Renal Medicine, St Vincents Hospital, Sydney, New South Wales, Australia \\ ${ }^{2}$ Department of Cardiology, St Vincents Hospital, Sydney, New South Wales, Australia \\ ${ }^{3}$ Department of Heart Failure and Transplantation, St Vincents Hospital, Sydney, New South Wales, Australia \\ ${ }^{4}$ Head of Department of Renal Medicine/ Director of Medicine, St Vincents Hospital, Sydney, New South Wales, Australia
}

*Corresponding author: Chris Anthony. MBBS Department of Cardiology, Renal Medicine, Heart Failure and Transplantation, St Vincents Hospital, Sydney, 1/569 George Street, Sydney-2000, New South Wales, Australia, Tel: 0061424132549; E-mail: chris007_7@hotmail.com/canthony@stvincents.com.au

\begin{abstract}
Tenckhoff catheter implantation and modified peritoneal dialysis as a novel therapeutic approach in diuretic resistant congestive heart failure: a single-centre case-series. Background: Progressive renal insufficiency and diuretic resistance represent significant challenges in the management of advanced heart failure, particularly in the context of intractable ascites due to Right Heart Failure (RHF). There is growing interest in the potential use of intermittent paracentesis and peritoneal dialytic ultra-filtration in this setting but clinical experience is limited.

Methods: We undertook retrospective analysis of changes in the following clinical parameters in six patients ( $66 \%$ males, average age 53 years) who underwent Tenckhoff catheter implantation (TCI) for the management of RHF-related intractable ascites i) body weight; ii) number of heart failure related admissions and time spent in hospital; and iii) diuretic requirements. Student t-test was performed to analyse statistical significance.

Results: Follow-up ranged from 4 to 16 weeks post TCI. Compared to immediately prior to TCI: i) $83 \%(5 / 6)$ of patients experienced an improvement in renal function; ii) average weight fell from $72.2 \pm 4.7$ to $67.7 \pm 3.9 \mathrm{~kg}$ (mean $\pm \mathrm{SEM}, \mathrm{p}=0.054)$; iii) none of the patients have required heart failure related admission compared to an average number of 40 days in hospital over 6.7 admissions in the twelve months preceding TCI and iv) frusemide dose decreased from $263 \pm 49$ to $140 \pm 50 \mathrm{mg} / \mathrm{day}, \mathrm{p}=0.051$ ). All patients report a subjective improvement in overall wellbeing and quality of life. One patient developed peritonitis which was controlled with antibiotic treatment without needing catheter removal.

Conclusion: Our experience supports the use of TCI as a therapeutic modality in patients with RHF and intractable ascites resistant to medical management.
\end{abstract}

Received Date: February 08, 2016
Accepted Date: March 22, 2016
Published Date: March 29, 2016

Citation: Anthony, C., et al. Tenckhoff Catheter Implantation in Refractory Ascites Due to Right Heart Failure. (2016) J Heart Cardiol 2(1): 12-16.

DOI: $10.15436 / 2378-6914.16 .020$

\section{Introduction}

Diuretic therapy is often utilized as first line therapy in patients with acute decompensated heart failure with fluid over$\operatorname{load}^{[1-4]}$. However there is an increasing incidence of heart failure that is refractory to diuretic therapy ${ }^{[5-9]}$. It is associated with high morbidity and mortality with average documented survival of $50 \%$ at 6 months ${ }^{[10]}$. With improved understanding of the physiology and techniques of peritoneal dialysis, ambulatory peritoneal ultrafiltration can be applied to the management of refractory heart failure in addition to conventional diuretic therapy with favourable outcomes ${ }^{[1-18]}$. The main advantages of ambulatory peritoneal ultrafiltration over conventional haemodialysis for fluid removal include less dysrhythmias, haemodynamic fluctuations and fluid shifts ${ }^{[19-22]}$. 
A further expansion of the peritoneal ultrafiltration technique is the implantation of a Tenckhoff catheter (TCI) to enable intermittent paracentesis as an adjunct to diuretic therapy in patients with refractory ascites due to malignancy, cirrhosis, renal failure and right heart failure. Its utility in these settings have been reported in case series and case reports to have beneficial and sustained impact on overall fluid balance and ascitic fluid volume ${ }^{[23-25]}$.

We describe our experience using this modality in the management of refractory ascites due to right heart failure.

\section{Method}

A retrospective single centre analysis of 6 patients with intractable ascites due to right heart failure who proceeded to Tenckhoff Catheter Implantation (TCI) was undertaken. Their baseline characteristics are tabulated in Table 1.

Table 1: Patient Characteristics

\begin{tabular}{|l|l|l|l|l|l|l|l|}
\hline Patient & Age & Sex & $\begin{array}{l}\text { Etiology of Cardio- } \\
\text { myopathy/NYHA } \\
\text { Class prior to TCI }\end{array}$ & $\begin{array}{l}\text { Weight (Kg) } \\
\text { prior to TCI }\end{array}$ & $\begin{array}{l}\text { Duration in hospital } \\
\text { pre implantation days/ } \\
\text { admissions per year }\end{array}$ & Diuretic use prior to TCI & $\begin{array}{l}\text { PD Regimen/ Intermittent } \\
\text { Paracentesis }\end{array}$ \\
\hline 1 & 69 & M & $\begin{array}{l}\text { DCM/ RHD } \\
\text { NYHA 3 }\end{array}$ & 90 & $29 / 6$ & $\begin{array}{l}\text { Frusemide 250 mg bd + Dith- } \\
\text { iazide 25 mg daily }\end{array}$ & Icodextrin overnight PD \\
\hline 2 & 44 & F & $\begin{array}{l}\text { Constrictive Peri- } \\
\text { carditis NYHA 3 }\end{array}$ & 57 & $49 / 7$ & $\begin{array}{l}\text { Frusemide } 80 \mathrm{mg} \text { tds + Spi- } \\
\text { ronolactone 25 mg daily + } \\
\text { dithiazide 12.5 mg bd }\end{array}$ & $\begin{array}{l}\text { Icodextrin BD UF } \\
25 \text { mg daily }\end{array}$ \\
\hline 3 & 67 & F & ICM NYHA & 69 & $40 / 4$ & $\begin{array}{l}\text { Frusemide } 160 \mathrm{mg} \text { bd + Spi- } \\
\text { ronolactone 50 mg daily }\end{array}$ & PD 3x/ day \\
\hline 4 & 49 & M & HCM NYHA 3 & 80 & $37 / 6$ & $\begin{array}{l}\text { Frusemide } 80 \mathrm{mg} \text { bd + Spi- } \\
\text { ronolactone 25 mg daily }\end{array}$ & $\begin{array}{l}\text { Intermittent } \\
\text { daily }\end{array}$ \\
\hline 5 & 50 & M & DCM NYHA 3 & 73 & $34 / 6$ & PD & Frusemide $120 \mathrm{mg} / 80 \mathrm{mg}$ \\
\hline 6 & 39 & M & HCM NYHA4 & 70 & $49 / 11$ & & \\
\hline
\end{tabular}

DCM: Dilated Cardiomyopathy; HCM: Hypertrophic Cardiomyopathy; RHD: Right Heart Disease; NYHA: New York Heart Association; ICM: Ischemic Cardiomyopathy; PD: Peritoneal Dialysis; BD: Twice daily; UF: Ultrafiltration;

These patients had failed to respond to maximal doses of diuretics including a combination of loop diuretics, thiazide diuretics and aldosterone receptor antagonist. They were deemed to be in refractory right heart failure by a consultant nephrologists and consultant heart transplant physician. All patients in these series were assessed by the same consultant physicians. All 6 patients were between NYHA class 3 and 4 at time of TCI (Table 2).

Table 2: Results

\begin{tabular}{|l|l|l|l|}
\hline Patient & Weight $(\mathrm{kg})$ & Diuretic use & Heart failure admissions/NYHA Class Post TCI \\
\hline 1 & 80 & Frusemide $120 \mathrm{mg}$ bd & Nil at 3 months/ NYHA 2 \\
\hline 2 & 56 & Frusemide $80 \mathrm{mg} \mathrm{bd}+$ HCT $12.5 \mathrm{mg}$ daily & Nil at 3 months NYHA 2 \\
\hline 3 & 62 & Frusemide $80 \mathrm{mg}$ daily & 1 admission for unrelated infection NYHA 1-2 \\
\hline 4 & 79 & Frusemide $160 \mathrm{mg}$ bd + Spironolactone $50 \mathrm{mg}$ daily & Nil at 3 months NYHA 2 \\
\hline 5 & 63 & Frusemide $40 \mathrm{mg}$ daily & Nil at 3 months NYHA1-2 \\
\hline 6 & 65 & CAPD & 1 admission for peritonitis NYHA3-4 \\
\hline
\end{tabular}

Patients were all educated on ascitic drain care and underwent education sessions supervised by trained dialysis nurses at $\mathrm{St}$ Vincents Hospital. Pts were instructed to do twice daily drains initially whilst the catheter was less than 2 weeks old. Once the site was healed, they were advised to perform daily drains. The transition and safety to proceed to once daily drains was supervised by the trained dialysis nurses. If the volume of drainage was consistently $<500 \mathrm{mls} /$ day, they were then instructed to continue to perform twice daily drains.

Patients remained on ascitic drainage without peritoneal dialysis unless they had significant deterioration in their renal function or adequate fluid balance was not satisfactorily attained. Clinically inadequate drainage was deemed as clinical edema on examination or symptomatic progression of shortness of breath due to increasing fluid overload.

Patients who required the transition to chronic ambulatory peritoneal dialysis underwent ultrafiltration on a regimen of $7.5 \%$ Icodextrin solution with an overall volume of $1.5 \mathrm{~L}$ to $2 \mathrm{~L}$ and a dwell time of 12 hours. Initially they were commenced on overnight dwells however this was increased to twice daily exchanges if they were unable to maintain fluid balance with single dwells. Changes in the following clinical parameters were reviewed and documented over a 12 month period divided into 6 months pre and 
post TCI implantation:

i) Body weight; ii) Number of heart failure related admissions;

iii) time spent in hospital; iv) Diuretic requirements.

Student t-test was then applied to ascertain statistical significance.

These results were then tabulated and analysed.

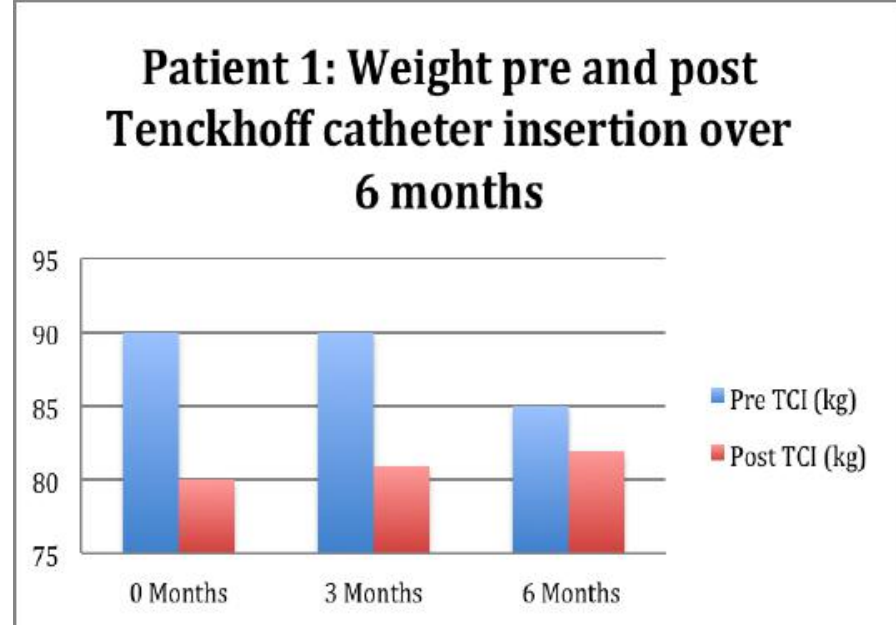

Patient 1:

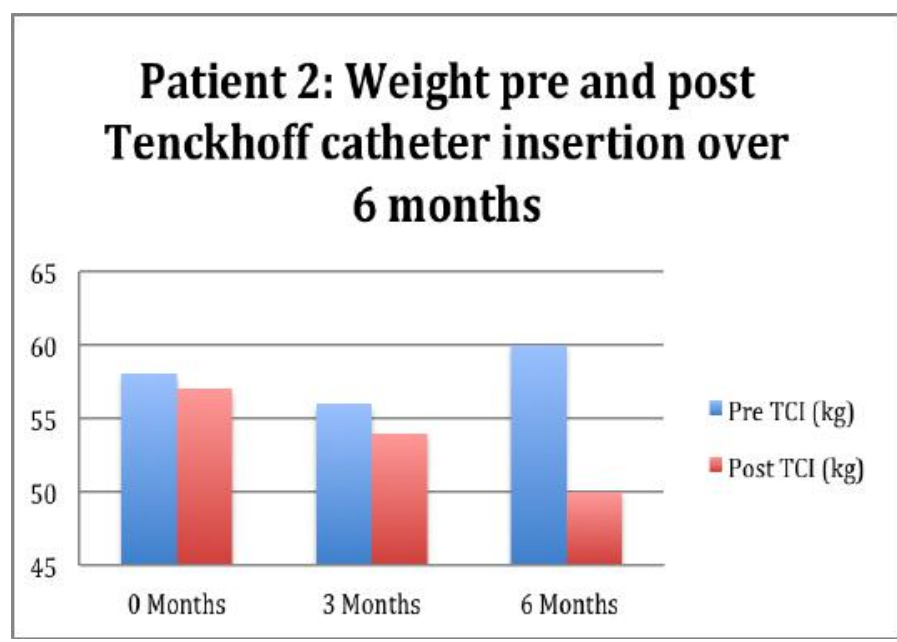

Patient 2

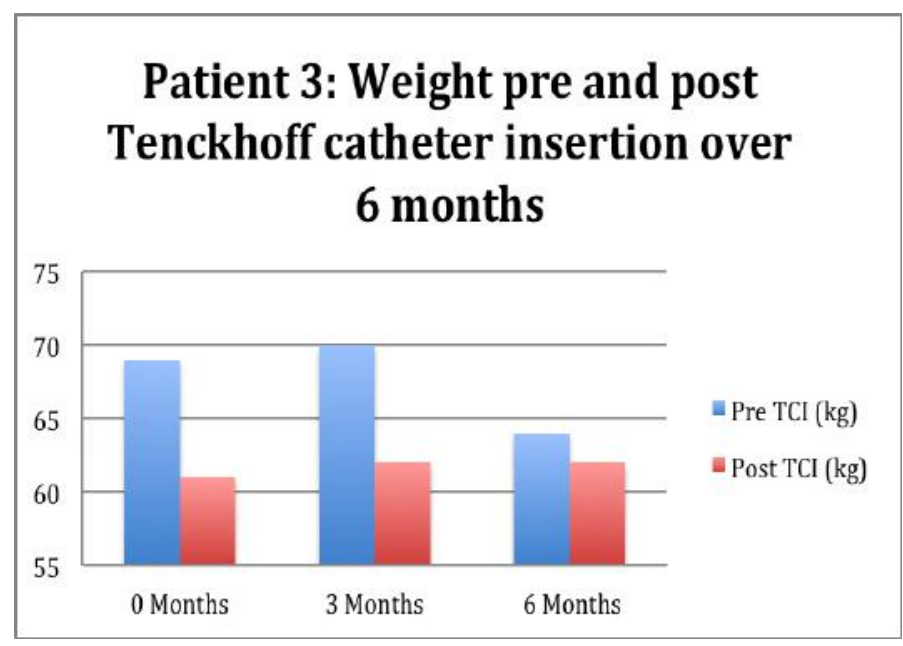

Patient 3

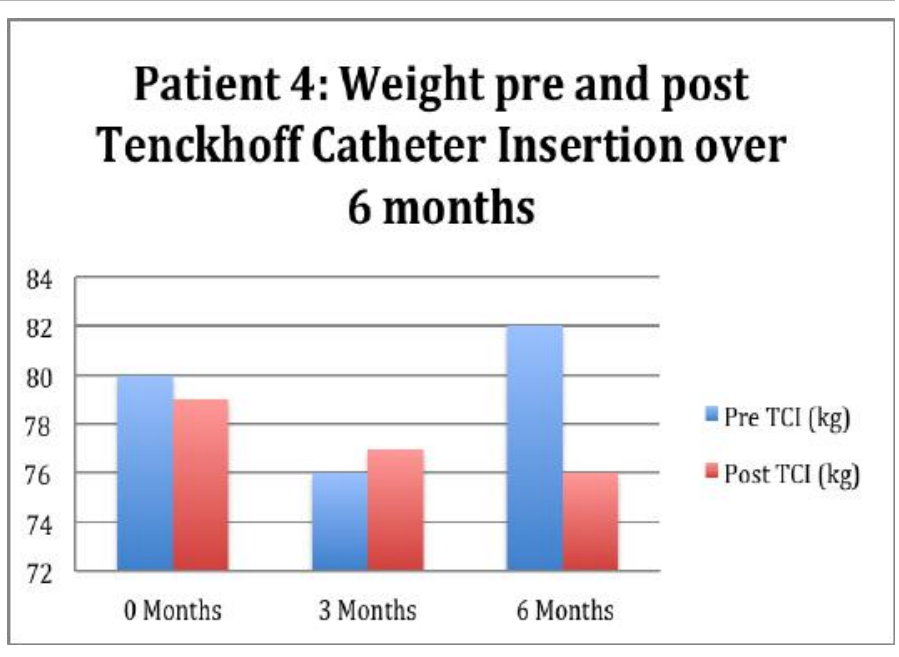

Patient 4

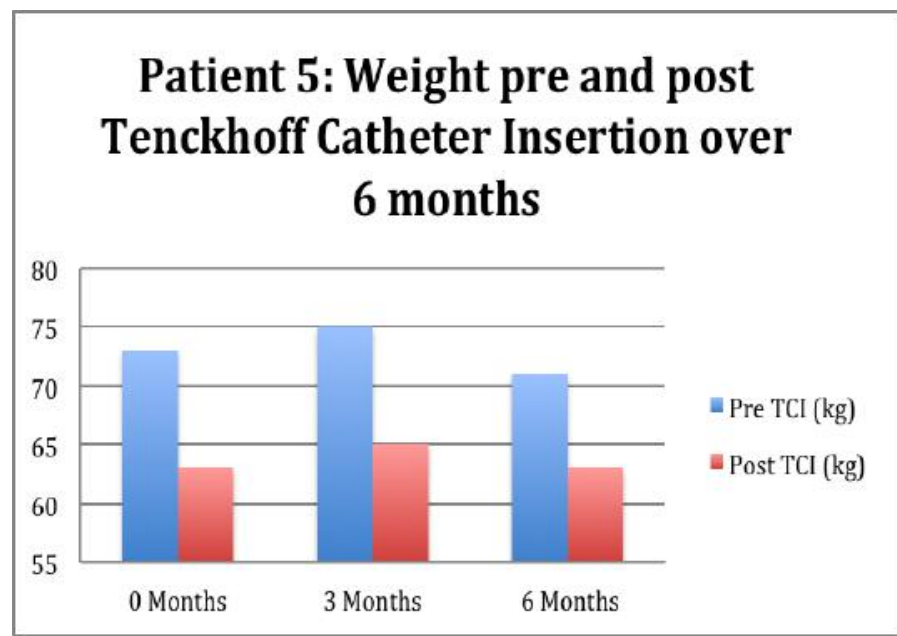

Patient 5

\section{Patient 6: Weight pre and post Tenckhoff Catheter Insertion over 6 months}

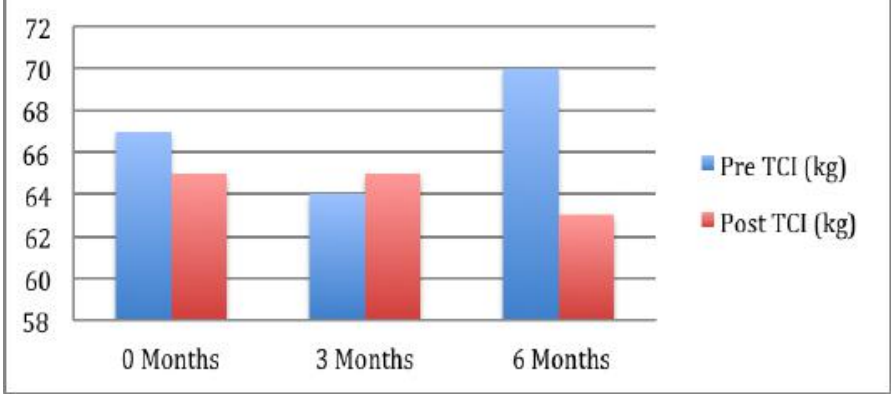

Patient 6

Figure 1: Graphical Representation of Weight Changes in the 6 months preceding and post TCI

\section{Results Continued}

Compared to prior to TCI $83 \%(5 / 6)$ of patients experienced an improvement in renal function. Table 2.

Their diuretic dose decreased from $263 \pm 49$ to $140 \pm$ $50 \mathrm{mg} /$ day, $\mathrm{p}=0.05$, demonstrating improved diuretic sensitivity with intermittent ambulatory PD use. Table 2

The average weight fell from $72.2 \pm 4.7$ to $67.7 \pm 3.9 \mathrm{~kg}$ 
$($ mean \pm SEM,$p=0.054)$. This is depicted graphically in Figure 1 where in the 6 months post TCI there was a marked and consistent improvement in average weight compared to 6 months pre TCI. Table 2

None of the patients were admitted for heart failure post TCI heart failure compared to an average number of 40 days in hospital over 6.7 admissions in the twelve months preceding TCI.

All patients report a subjective improvement in overall wellbeing and quality of life. 4 patients experienced an objective improvement in NYHA class within the first month of TCI.

Of the 6 patients, 4 transitioned onto a full dialysis/ APD prescription due to end stage renal failure. 1 out of the 6 patients required APD from the offset due to poor renal function.

One patient developed peritonitis that was controlled with antibiotic treatment without needing catheter removal

\section{Discussion}

We have described 6 patients with refractory heart failure and ascites, unresponsive to medical management who showed a rapid and sustained improvement in symptoms and quality of life with the use of intermittent ambulatory peritoneal dialysis. This was potentially due to the enhanced removal of sodium and water through the utility of ultrafiltration into the peritoneal cavity ${ }^{[26]}$.

This facilitates more effective driving of fluid from the interstitium back into the intravascular space, improving fluid removal, renal perfusion and renal function ${ }^{[26]}$. This is mirrored in the results of RAPID- CHF and the UNLOAD trials that showed ultrafiltration resulted in more fluid removal and weight loss than treatment with diuretics ${ }^{[27,28]}$. Several other studies have also demonstrated more effective fluid removal with ultrafiltration with the limitation of a diuretic only control arm ${ }^{[29-32]}$. This benefit was also shown with the utility of peritoneal dialysis in Mehrotra et al, Khalifeh et al and Sanchez et al ${ }^{[15-17]}$.

In addition there was an added benefit of regaining diuretic sensitivity in PD use which was also demonstrated in our case series where 5 out of 6 of our patients had a reduction and improved diuresis with lower doses of diuretic therapy ${ }^{[15]}$.

In our cohort, 4 out of the 6 patients who initially were on icodextrin prescriptions progressed to requiring 9 hour treatments on automated peritoneal dialysis for ultrafiltration. 3 of these patients subsequently developed end stage renal failure which necessitated a dialysis prescription in addition to the ultrafiltration. 2 of these 3 patients were placed on a combined heart kidney transplant list due to progression of both their heart and kidney failure.

The UNLOAD study and a case series of 25 patient treated with ultrafiltration also showed a decrease in rehospitalisation and overall hospitalizations in the ultrafiltration cohort $^{[28,29]}$. This potentially reduces the incidence of the myriad of complications associated with recurrent hospital admissions and in our series led to improvement in patient quality of life measures and general state of well being.

The major complication associated with TCI are catheter and procedure related complications mainly bleeding and peritonitis. One of our patients did develop PD peritonitis but this was successfully managed with oral and intraperitoneal antibiotics that negated the need for Tenckhoff catheter removal, with minimal interruption to his CAPD regimen.

\section{Conclusion}

At this time there remains no effective decongestive treatment for patients with acute decompensated heart failure and refractory ascites. The utility of TCI and intermittent ambulatory peritoneal dialysis for more efficient and sustained fluid removal may lead to overall improvement in fluid balance and symptomatic relief.

Conflicts of Interest: No disclosures in the submission of this work.

\section{References}

1. Hunt, S.A., Baker, D.W., Chin, M.H., et al. ACC/AHA guidelines for the management of chronic heart failure in the adult: executive summary. A report of the American college of Cardiology/ American Heart Association Task Force on Practice Guidelines (Committee to revise the 1995 Guidelines for the evaluation and Management of Heart Failure). (2001) J Am Coll Cardiol 38(7): 2101-2113.

2. Adams, K.F.Jr., Fonarow, G.C., Emerman, C.L., et al. Characteristics and outcomes of patients hospitalised or heart failure in the United States: rationale, design and preliminary observations from the first 100,000 cases in the Acute Decompensated Heart Failure Registry (ADHERE). (2005) Am Heart J 149(2): 209-216.

3. Jesup, M., Abraham, W.T., Casey, D.E., et al. 2009 Focused update: ACCF/AHA Guidelines for the diagnosis and management of Heart Failure in Adults: a report of the American College of Cardiology Foundation/ American Heart Association Task Force on Practice Guideline: developed in collaboration with the International Society for Heart and Lung Transplantation. (2009) Circulation 119(14): 1977-2016.

4. Faris, R., Flather, M.D., Purcell, H., Poole-Wilson, P.A., et al. Diuretics for heart failure. (2006) Cochrane Database Syst Rev 1: CD003838. 5. Freda, B., Slawsky, M., Malidi, J., et al. Decongestive Treatmemt of Acute Decompensated Heart Failure: Cardiorenal Implications of Ultrafiltration and Diuretics. (2011) Am J Kidney Dis 58(6): 1005-1017.

6. Elilison, D.H. Diuretic therapy and resistance in congestive heart failure. (2001) Cardiology 96(3-4): 142-143.

7. Kramer, B.K., Schweda, F., Riegger, G.A. Diuretic treatment and diuretic resistance in heart failure. (1999 Am J Med 106(1): 90-96.

8. Ravnan, S.L., Ravnan, M.C., Deedwania, P.C. Pharmacotherapy in congestive heart failure: diuretic resistance and strategies to overcome resistance in patients with congestive heart failure. (2002) Congest Heart Fail 8(2): 80-85.

9. Liang, K.V., Williams, A.W., Greene, E.L., et al. Acute decompensated heart failure and the cardiorenal syndrome. (2008) Crit Care Med 36(1 suppl): S75-S88.

10. Jessup, M., Brozena, S. Heart failure. (2003) N Engl J Med 348(20): 2007-2018

11. Colona, P., Sorino, M., D' Agostino, C. et al. Nonpharmacologic care of heart failure: counselling, dietary restriction, rehabilitation, treatment of sleep apnea, and ultrafiltration. (2003) Am J Cardiol 91(9A): 41F-50F.

12. Bercu, V., Heinz, J., Anderson, R. Treatment of congestive cardiac failure with peritoneal dialysis. (1963) J Mich Med Sci 62: 1105.

13. Donato, L., Biagini, A., Contini, C., et al. Treatment of end stage congestive heart failure by extracorporeal ultrafiltation. (1987) Am J Cardiol 59(4): 379-380.

14. Tormey, V., Conlon, P.J., Horgan, F.J., et al. Long term successful management of refractory congestive cardiac failure by intermittent ambulatory peritoneal ultrafiltration. (1996) QJM 89(9): 681-683.

15. Mehrotra, R., Khanna, R. Peritoneal ultrafiltration for chronic congestive heart failure: rationale, evidence and future. (2001) Cardiology 
96(3-4): 177-182.

16. Khalifeh, N., Vychytil, A., Horl, W.H. The role of peritoneal dialysis in the management of treatment resistant congestive heart failure: a European perspective. (2006) Kidney Int Suppl 103: S72-S75.

17. Sanchez, J.E., Rodriguez, C., Gonzalez, I., et al. Analysis of the advantages of peritoneal dialysis in the treatment of chronic refractory heart failure. (2010) Nefrologia 30(5): 487-489.

18. Kagan, A., Rapoport, J. The role of peritoneal dialysis in the treatment of refractory heart failure. (2005) Nephrol Dial Transplant 20(Suppl 7): vii28-vii31.

19. Grushka, E., Garty, J., Kristal, B., et al. Cardiac arrhythmia in chronic renal failure: Holter monitoring during haemodialysis and intermittent peritoneal dialysis. (1990) Isr J Med Sci 26(7): 378-382.

20. Maiorca, R., Cancarini, G.C., Brunori, G., et al. Morbidity and mortality of CAPD and haemodialysis. (1993) Kidney Int 40: S4-S15.

21. Wizemann, V., Timio, M., Alpert, M.A., et al. Options in dialysis therapy: significance of cardiovascular findings. (1993) Kidney Int 40(suppl): S85-S91.

22. Marczewski, K., Wojcik, J., Janicka, L., et al. Arrhythmia in patients on dialysis treatment for chronic renal failure. (1990) Wiad Lek 43(8): 313-317.

23. Tse, K.C., Li, F.K., Tang, S., et al. Peritoneal dialysis in patients with refractoy ascites. (2001) Peritoneal Dialysis International 21(6).

24. Lee, A., Lau, T.N., Yeong, K.Y. Indwelling catheters for the management of malignant ascites. (2000) Support Care Cancer 8(6): $493-$ 499.
25. Barnett, T.D., Rubins, J. Placement of a permanent tunneled peritoneal drainage catheter for palliation of malignant ascites: A simplified percutaneous approach. (2002) J Vasc Interv Radiol 13(4): 379-383.

26. Popovich, R.P., Pyle, W.K., Moncrief, J.W. Kinetics of peritoneal transport. In: Nolph KD, ed. Peritoneal dialysis. (1981) Boston, Martinus Nijhoff Publishing 79-123.

27. Bart, B. A., Boyle, A., Bank, A.J., et al. Ultraflitration versus usual care for hospitalized patients with heart failure: the Relief for Acutely Fluid -Overloaded Patients with Decompensated Congestive Heart Failure (RAPID-CHF) trial. (2005) J Am Coll Cardiol 46(11): 20432046.

28. Costanzo, M.R., Guglin, M.E., Saltzberg, M.T., et al. Ultrafiltration versus intravenous diuretics for patients hospitalized for acute decompensated heart failure. (2007) J Am Coll Cardiol 49(6): 675-683.

29. Bartone, C., Sahir, S., Menon, S.G., et al. Comparison of ultrafiltration, nesiritide and usual care in acute decompensated heart failure. (2008) Congest Heart Fail 14(6): 298-301.

30. Liang, K.V., Hiniker, A.R., Williams, A.W., et al. Use of novel ultrafiltration device as a treatment strategy for diuretic resistant, refractory heart failure: initial clinical experience in a single center. (2006) J Card Fail 12(9): 707-714.

31. Costanzo, M.R., Saltzberg, M., O'Sullivan, J., et al. Early ultrafiltration in patients with decompensated heart failure and diuretic resistance. (2005) J Am Coll Cardiol 46(11): 2047-2051.

32. Jaski, B.E., Romeo, A., Ortiz, B., et al. Outcomes of volume overloaded cardiovascular patients treated with ultrafiltration. (2008) J Card Fail 14(6): 515-520. 